\title{
Social Organization and Activity Patterns of Common Warthog (Phacochoerus africanus Gmelin, 1788) in Dabena Valley Forest, Western Ethiopia
}

\author{
Alemayehu Edossa ${ }^{1,}$, , Afework Bekele ${ }^{2}$, Habte Jebessa Debella ${ }^{2}$ \\ ${ }^{1}$ Department of Biology, Adama Science and Technology University, Adama, Ethiopia \\ ${ }^{2}$ Department of Zoological Sciences, Addis Ababa University, Addis Ababa, Ethiopia \\ Email address: \\ alemayehuedossa1@gmail.com (A. Edossa) \\ ${ }^{*}$ Corresponding author
}

To cite this article:

Alemayehu Edossa, Afework Bekele, Habte Jebessa Debella. Social Organization and Activity Patterns of Common Warthog (Phacochoerus africanus Gmelin, 1788) in Dabena Valley Forest, Western Ethiopia. Ecology and Evolutionary Biology. Vol. 5, No. 4, 2020 , pp. $173-181$. doi: $10.11648 /$ j.eeb. 20200504.18

Received: October 5, 2020; Accepted: October 24, 2020; Published: November 27, 2020

\begin{abstract}
Studies on social organization and activity patterns of common warthog (Phacochoerus africanus Gmelin, 1788) was conducted in southwestern and northeastern Dabena Valley Forest from May 2016 to June 2018. These were in Gassi Controlled Area (GCHA) the southwestern part and in Haro Aba Diko Controlled Hunting Area (HADCHA); the northeastern part of the Valley. Group sizes of common warthogs whose center were on or very near the strip line transect were detected using binoculars and naked eyes. Population structure and group categories were recorded. Observations on diurnal activity patterns were carried out using naked eyes and binoculars. The duration of each activity was recorded using mobile electronic stopwatch. Continual scan sampling methods were used to assess the activity budgets of common warthog populations. The sounder size of common warthog population in GCHA was 246, in HADCHA, it was 652. The population size in the study areas showed a significant difference $\left(\chi^{2}=18.78, \mathrm{df}=1, \mathrm{P}=0.05\right)$. The highest common warthog population sounder was formed by unidentified juvenile sex: $235(26.5 \%)$, followed by sub-adult male: $191(21 \%)$. During the wet season, the adult male common warthog population sounder size was significantly different (Mann- Whitney: $U=1.5, P<0.005$ ) compared to the subadult female. There were significant differences in walking $\left(\mathrm{F}_{122}=6.65, \mathrm{P}<0.05\right)$ and vigilance $\left(\mathrm{F}_{122}=26.21, \mathrm{P}<0.05\right)$ between GCHA and HADCHA during the wet season. Adult common warthogs spent the highest proportion of the daytime feeding (47.21\%), followed by resting (14.29\%) and walking (11.94\%).
\end{abstract}

Keywords: Activity Patterns, Common Warthog, Dabena Valley Forest, Social, Organization, Western Ethiopia

\section{Introduction}

Common warthogs are communal animals with a flexible social structure [15]. They live in relative groups called sounders, consisting of one or more females with one or more successive litters [33]. Male warthogs usually depart from their natal groups before the age of two years [33, 39, 42]. Both sexes reveal a high degree of philopatry. Warthogs exist in clans, which comprise some groups of sounders whose home ranges overlap significantly with other sounders owing to the same clan [33, 42]. Common warthog group formation depends on sex, age and season of the year [42] Adult males seldom form sounders [15, 42]. Closely related philopatric females usually form a sounder as investigated by [18] and [35]. Grouping behavior in adult females is more complex, and two obvious reproductive strategies are practiced [42]. These constitute: adult females that rear their young alone and those that rear their young in sounders with other individuals. Hence, unidentified juvenile sexes of common warthogs are rarely seen alone [15, 42]. The tendency of sounder formation is limited by resource competition. Predation possibly influences sounder structure [39, 42]. Seasonal variation may influence group formation within and among ungulate species [18, 40]. Hence, common warthog grouping behavior changes as a function of season and become fragmented during the dry season because of competition for resources [33, 42]. Seasonal 
changes in sounder size and their composition also depend on reproductive patterns and separation for parturition of females $[18,35]$. Therefore, sounder formation benefits individuals of common warthogs through predator detection, increased vigilance and dilution effects $[12,42]$. It also helps to locate food resources [42].

During the morning and afternoon hours when weather conditions are neither too cold nor too hot, looking for food is the primary consideration of most mammals [24, 28]. During the mid-day hours when conditions are hot, animals might need to move into shaded sites for resting [17, 23, 24]. However, there is variation in activity patterns of time budget among mammalian populations [2]. Hence, common warthogs are active during the day. They sleep in holes usually neglected by other animals during the night, which is unusual in other ungulates $[15,38]$.

Common warthogs scan their environment when they recognize predators and there is difference in forage quality between habitats $[13,15]$. Scanning in warthogs is least in abundant grasses [6]. According to [13] and [15], olfaction together with vocalization and hearing, are important communication tools. Family groups communicate each other with different sounds as squeaks, growls, chirps, and grunts. Warthogs love to roll in mud [13]. The mud covers their hairless skin; keeping them cool and protecting them from biting flies and other insects $[10,38]$.

\section{Materials and Methods}

\subsection{Description of the Study Areas}

Ethiopia is one of the East African countries rich in flora and fauna diversities. Common warthogs are widely distributed throughout DVF of western part of the country. To facilitate and manage the study, DVF was divided into two. The southwestern side of DVF was named GCHA and the northeastern side, HADCHA. The Dabena River borders the two (Figures 1 and 2). The vegetation type of the DVF was identified as Cumbretum- Terminalia, open grassland and riparian forest. DVF encompasses different medium sized and large mammalian species. These include; buffalo (Syncerus caffer), common warthog (Phacochoerus africanus), bush pig (Potamocherus larvatus), giant forest hog (Hylochoerus meinertzhageni), bushbuck (Tragelaphus scriptus), Guenther's dik-dik (Madoqua guentheri) and waterbuck (Kobus ellipsipprymu). Vervet monkeys (Chlorocebus pygerythrus), olive baboon (Papio anubis), savanna baboon (Papio cynocephalus), blue monkeys (Cercopithecus mitis), colobus monkey (Colobus guereza), Aardvark (Orycteropus afer). These herbivores have a large impact on the savanna vegetation by changing and maintaining ecosystem properties such as nutrient cycling, productivity and plant species composition. It also harbors lion (Panthera leo), leopard (Panthera paradus), spotted hyaena (Crocuta crocuta), African civet (Civettictis civetta), cheetah (Acinonyx jubatus), honey badger (Mellovora capensis) and common jackal (Canis aureus) are among the large mammals species of the study area. The vegetations of the area provide forage and water sources for these wild animals.

\subsubsection{Gassi Controlled Hunting Area (GCHA)}

Gassi Controlled Hunting Area (GCHA) is located in the Oromia Regional State, BunoBedelle Administrative Zone. Most of the study sites lie in Meko and Dabohanna districts, along the Banks of the Dabena River. It is located approximately $600 \mathrm{~km}$ west of Addis Ababa. Gassi Controlled Hunting Area is situated in the southwestern part of Dabena

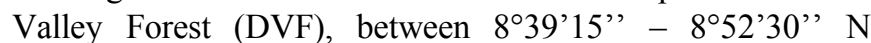
latitude and $35^{\circ} 55^{\prime} 30^{\prime \prime}-36^{\circ} 7^{\prime} 15^{\prime \prime}$ ' E longitude. The elevation ranges from 1,538 to $1689 \mathrm{~m}$ asl (Figure 1). Gassi and Miesso rivers drain in Dabena River. Dabena Valley Forest (DVF) is situated within the Didessa River sub-basin. Didessa River is the second catchment area of Abay basin next to Dabus, the largest drainage of the upper Blue Nile River Basin [7, 20]. Didessa and Dabus rivers drain the southwestern part of the basin, and contribute one third of the total flow of the Grand Ethiopian Renaissance Dam [8] which is the main sediment source of the Nile River [3]. Gassi controlled hunting area was demarcated as a controlled hunting area in 2007 with an estimated total area of $24,000 \mathrm{~h}$ at hat includes CombretumTerminalia woodland and riparian forest.

\subsubsection{Haro Aba Diko Controlled Hunting Area (HADCHA)}

Haro Aba Diko Controlled Hunting Area (HADCHA) is located in the Oromia Regional State, Buno Bedelle Administrative Zone of Ethiopia. It is approximately $550 \mathrm{~km}$ west of Addis Ababa on Addis Ababa, Nekemte-Gimbi road along the western lowland of the country. Haro Aba Diko Controlled Hunting Area is situated along the northeastern part of Dabena Valley Forest (DVF) between $8^{\circ} 35^{\prime} 20^{\prime \prime}$ $8^{\circ} 45^{\prime} 55^{\prime \prime} \mathrm{N}$ latitude and $36^{\circ} 15^{\prime} 45^{\prime \prime}-36^{\circ} 20^{\prime} 10^{\prime \prime}$ E longitude The elevation ranges from 1,646 to 1,720 masl (Figure 2). HADCHA was demarcated in 2007 with an estimated total area of 53,841 ha that includes savanna woodland and riparian forest. It is one of the controlled hunting areas in the western Ethiopia that could be used as the future carbon sequestration center of the country.

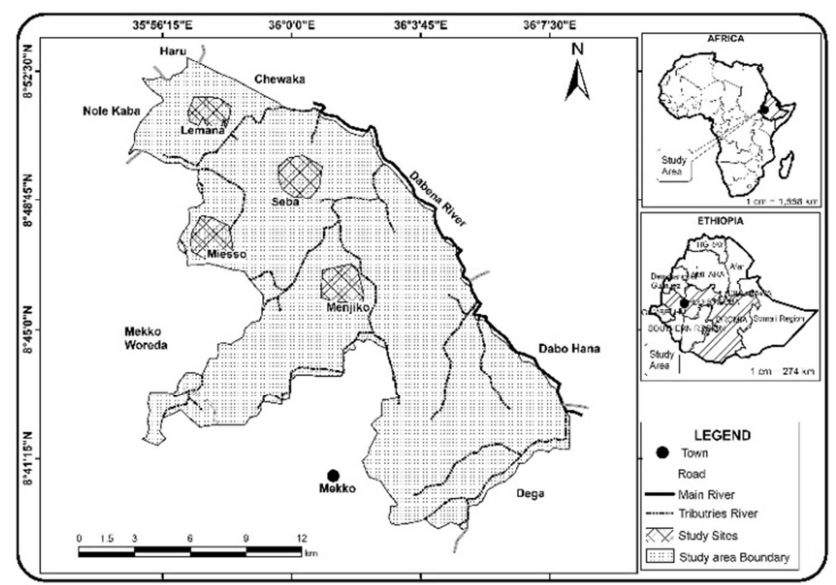

Figure 1. Location map of Gassi Controlled Hunting Area. 


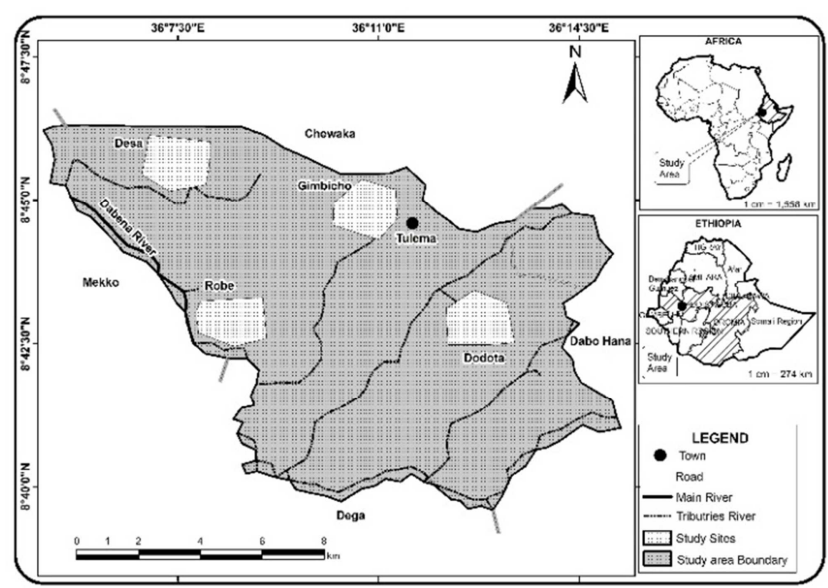

Figure 2. Map of Haro Aba Diko Controlled Hunting Area.

\subsection{Methods}

Social organization and diurnal activity patterns of common warthogs were studied in Dabena Valley Forest (DVF) in (GCHA and HADCHA) from December 2017 to June 2018 that included wet and dry seasons. Data on social organization and diurnal activity of common warthog were collected from eight randomly assigned study sites: Robe, Desa, Gimbicho and Dodeta in HADCHA and Miesso, Seba, Lemana and Menjiko sites in GCHA. Group sizes of common warthogs whose centers were on or very near the strip line transect and diurnal activity patterns were detected using binoculars and naked eyes [11, 32, 41]. Population structure and group categories were recorded. Body size, shoulder height and tusk size or lengths were used to determine the approximate age [34, 42]. Sexual characteristics, presence and absence of teats and body size were used to determine sex. Stratification by group types that included adult males and females, sub-adult male and females and unidentified sex of juveniles were stratified by seasons and recorded in the data sheet $[14,32]$.

The duration of each activity was measured using mobile electronic stopwatch. Each day was divided into three time blocks: morning $(7: 00-10: 00 \mathrm{~h})$, mid-day $(12: 00-14: 00$ p.m.) and afternoon (15:00 -18:00 h). Continual scan sampling methods were used as adopted by [16], [29], and [30] to assess the activity budgets of common warthog populations. Eight separate focal sample observations sites were randomly selected [5]. Four sightings were in Combretum-Terminalia woodland and two were in each of the grassland habitats and riparian forests. Focal animal observation was facilitated in the animal's preferences for short grass areas during the wet season and on the newly growing grasses after fire during the dry season by sitting on strategic sites on elevated places and tree branches. When the observed animal disappeared from view, the time interval that the animals out of sight were recorded and another individual was randomly selected and monitored [29].

Frequent activities of male and female common warthogs in each sounder were detected and recorded on the data sheet at ten minutes interval time. Infrequent activities such as defecation, urination, alarm calling, and others were rejected to handle the major once [30]. Thus, a total of 1,024 observations of daily activities of male and female common warthog were made during the wet and dry seasons of the study period. Daily activity data were collected from 16 common warthog populations, 8 from each sex. Daily time budget of both sexes were calculated by summing all observations per day.

The percentage of time engaged in the six main behaviors were calculated for each individual male and female of common warthogs by dividing the number of incident of a particular behavior by the total number of sightings within that time block $[16,30]$. The behavioral data were then organized across all the sites and averaged for each sex and season.

$$
\frac{\Sigma(\text { recorded activity } \mathrm{X})}{\sum(\text { recorded of all activities })} \times 100 \%
$$

The following were the main behaviors observed:

1. Feeding - stand/walk and eat

2. Resting - lying on the ground

3. Walking/ running- moving and override

4. Vigilance- watchfulness and careful observation of the animal, whilst standing, assumes an alert posture and stares fixedly on a specific point with both ears forward; the animal may produce an alarm snort or stamp the ground with one leg.

5. Salt licking-digging the ground

6. Wallowing- rolling in the mud: undulating in water containing ground

\subsection{Data Analysis}

Time spent by adult males and females dedicated to the six main behavioral activities during the three time blocks were compared using $\mathrm{M} \pm \mathrm{SE}$ with the data pooled for both seasons and sex [30]. ANOVA was used to evaluate the mean duration of time engaged in the major behavioral activities. Mann-Whitney $U$ test was used to compare differences between two sounders of common warthog populations across each study sites $[9,36]$. The percentage and mean time attained of each major behavioral activities of adult common warthog individuals during the wet and dry seasons were calculated using Chi-square test. It also identified the behavioral variation found between the two study areas [29, 30].

\section{Results}

The largest adult male of common warthog sounder size was 88 in HADCHA and the smallest was in GCHA (29). But, the variation was not significant $\left(\chi^{2}=4.32, \mathrm{df}=1\right.$, $\mathrm{P}=0.05)$. Adult female group size was maximum in HADCHA (118) and minimum in GCHA (46). They revealed significant differences $\left(\chi^{2}=5.67, \mathrm{df}=1, \mathrm{P}=0.05\right)$. Sub-adult male group size was highest in HADCHA (139) and lowest in GCHA (52) and they were significantly 
different $\left(\chi^{2}=5.88, \mathrm{df}=1, \mathrm{P}=0.05\right)$. The maximum sub-adult female group size was hosted by HADCHA (134) and the minimum by GCHA (54). They were significantly different $\left(\chi^{2}=5.83, \mathrm{df}=1, \mathrm{P}=0.05\right)$. The largest unidentified juvenile sex group size was recorded in HADCHA (173) and the smallest in GCHA (65). They revealed significant variation $\left(\chi^{2}=6.78, \mathrm{df}=1, \mathrm{P}=0.05\right)$. All sounder size of common warthog population in GCHA was 246 and in HADCHA, it was 652 totaling 898 during both seasons. Therefore, they showed significant differences $\left(\chi^{2}=18.78, \mathrm{df}=1, \mathrm{P}=0.05\right)$ (Figure 3).

The highest common warthog population sounder was formed by unidentified juvenile sex as 235 (26.5\%), followed by sub-adult male $191(21 \%)$. The lowest by adult male was $117(13 \%)$ in both study areas during the wet and dry seasons. There was a significant difference $\left(\chi^{2}=16.12\right.$, $\mathrm{df}=4, \mathrm{P}=0.001$ ) among the common warthog population sounder of the study areas (Figure 4). In GCHA, sounder size of adult males $\left(\chi^{2}=2.51 \mathrm{df}=1, \mathrm{P}=0.05\right)$, sub-adult males $\left(\chi^{2}=3.52 \mathrm{df}=1, \quad \mathrm{P}=0.05\right)$ and unidentified juvenile sex $\left(\chi^{2}=3.11 \mathrm{df}=1, \mathrm{P}=0.07\right)$ were not influenced by seasons. In contrast, sounder size of adult females $\left(\chi^{2}=5.68 \mathrm{df}=1\right.$, $\mathrm{P}=0.05)$ and sub-adult females $\left(\chi^{2}=5.46 \mathrm{df}=1, \mathrm{P}=0.05\right)$ were influenced by season. Post hoc comparisons revealed adult female and sub-adult female sounder sizes were significantly larger during the dry season than the wet season in GCHA (Table 1). During the wet season, adult males of common warthog population sounder size was significantly different (Mann- Whitney: $U=1.5, P<0.005$ ) from sub-adult females. Sounder size of $\mathrm{AF}$ and SAM $(\mathrm{U}=7.5, \mathrm{P}<0.005), \mathrm{AF}$ and $\mathrm{SAF}(\mathrm{U}=7, \mathrm{P}<0.005)$, and $\mathrm{AF}$ and UJS ( $U=6, P<0.005)$ were significantly different. In GCAH during the dry season, AM and AF, AM and SAM, AM and UJS and AF and SAM sounders were significantly different $(\mathrm{P}<0.005)$ (Table 1).

In HADCHA, sounder size of adult males $\left(\chi^{2}=2.08 \mathrm{df}=1\right.$, $\mathrm{P}=0.05)$, sub-adult males $\left(\chi^{2}=3.07 \mathrm{df}=1, \mathrm{P}=0.05\right)$ and subadult females $\left(\chi^{2}=3.61 \mathrm{df}=1, \mathrm{P}=0.05\right)$ were not influenced by seasons. Contrary to this, sounder size of adult female $\left(\chi^{2}=5.16 \mathrm{df}=1, \quad \mathrm{P}=0.05\right)$ and unidentified juvenile sex $\left(\chi^{2}=6.01 \mathrm{df}=1, \mathrm{P}=0.05\right)$ groups were influenced by season. Post hoc comparisons revealed adult male, adult female and unidentified juvenile sex sounder sizes were significantly larger during the dry season than the wet season in HADCHA (Table 1). In HADCHA during the wet season, AM and AF $(\mathrm{U}=3, \mathrm{P}<0.005), \mathrm{AM}$ and $\mathrm{SAM}(\mathrm{U}=2, \mathrm{P}<0.005), \mathrm{AM}$ and SAF $(\mathrm{U}=3, \mathrm{P}<0.005), \mathrm{AF}$ and SAM $(\mathrm{U}=4.5, \mathrm{P}<0.005)$, and $\mathrm{AF}$ and $\mathrm{SAF}(\mathrm{U}=5.5, \quad \mathrm{P}<0.005)$ sounder size were significantly different. On the other hand, sounder size of AF and UJS, SAM and SAF, SAM and UJS, and SAF and UJS were significantly different $(\mathrm{P}<0.005)$. In HADCHA, the sounder size of $\mathrm{AM}$ and $\mathrm{AF}(\mathrm{U}=2.5, \mathrm{P}<0.005), \mathrm{AM}$ and SAM $(U=1.5, P<0.005), A M$ and $\operatorname{SAF}(U=2, P<0.005)$, and $\mathrm{AF}$ and $\mathrm{SAM}(\mathrm{U}=5, \mathrm{P}<0.005)$ showed significant variations during the dry season. Furthermore, AF and SAF $(\mathrm{U}=3.5, \mathrm{P}<$ $0.005)$, SAM and SAF ( $\mathrm{U}=7.5, \mathrm{P}<0.005)$, and SAM and UJS $(\mathrm{U}=2, \mathrm{P}<0.005)$ were significantly different (Table 1$)$.
Table 1. Seasonal variation in sounder size of common warthog in GCHA and $H A D C H A$.

\begin{tabular}{|c|c|c|c|c|c|c|c|}
\hline \multirow{2}{*}{ study site } & & \multicolumn{2}{|c|}{ Season } & \multicolumn{3}{|c|}{ Sounder } & \multirow{2}{*}{ Total } \\
\hline & & $\mathbf{A M}$ & AF & SAM & SAF & UJS & \\
\hline \multirow[t]{2}{*}{ Miesso } & w & 2 & 5 & 3 & 3 & 4 & 17 \\
\hline & $\mathrm{d}$ & 5 & 6 & 7 & 8 & 11 & 37 \\
\hline \multirow[t]{2}{*}{ Seba } & w & 3 & 7 & 6 & 7 & 7 & 30 \\
\hline & $\mathrm{d}$ & 6 & 8 & 11 & 10 & 11 & 46 \\
\hline \multirow[t]{2}{*}{ Lemana } & w & 1 & 3 & 4 & 3 & 4 & 15 \\
\hline & $\mathrm{d}$ & 3 & 5 & 5 & 7 & 6 & 26 \\
\hline \multirow[t]{2}{*}{ Menjiko } & w & 2 & 4 & 5 & 6 & 7 & 24 \\
\hline & $\mathrm{d}$ & 7 & 8 & 11 & 10 & 15 & 51 \\
\hline \multirow[t]{2}{*}{ Robe } & $\mathrm{w}$ & 5 & 7 & 8 & 9 & 12 & 41 \\
\hline & $\mathrm{d}$ & 10 & 14 & 16 & 15 & 22 & 77 \\
\hline \multirow[t]{2}{*}{ Desa } & $\mathrm{w}$ & 7 & 11 & 13 & 12 & 21 & 64 \\
\hline & $\mathrm{d}$ & 13 & 17 & 20 & 21 & 26 & 97 \\
\hline \multirow[t]{2}{*}{ Gimbicho } & $\mathrm{w}$ & 11 & 16 & 20 & 18 & 23 & 88 \\
\hline & $\mathrm{d}$ & 16 & 20 & 21 & 22 & 27 & 106 \\
\hline \multirow[t]{2}{*}{ Dodeta } & $\mathrm{w}$ & 9 & 12 & 16 & 15 & 18 & 70 \\
\hline & $\mathrm{d}$ & 17 & 21 & 25 & 22 & 24 & 109 \\
\hline
\end{tabular}

$\mathrm{AM}=$ adult male, $\mathrm{AF}=$ Adult female, $\mathrm{SAM}=$ sub-adult male, $\mathrm{SAF}=$ sub-adult female, UJS=unidentified juvenile sex

The two study areas showed significant variations in subadult female $\left(\mathrm{F}_{1,6}=15.9, \mathrm{P}<0.05\right)$ and in unidentified juvenile sex $\left(\mathrm{F}_{1,6}=26, \mathrm{P}<0.05\right)$ per study site during the wet season. Consequently, HADCHA supported more mean number of sounders of common warthogs than GCHA (Figure 5). During the dry season, the mean number of adult male common warthogs per study site was $5.25 \pm 0.85$ in GCHA and $14 \pm 1.58$ in HADCHA. Thus, there were significant differences between the study areas in adult male $\left(\mathrm{F}_{1,6}=23.71\right.$, $\mathrm{P}<0.05)$, adult female $\left(\mathrm{F}_{1,6}=41.33, \mathrm{P}<0.05\right)$ and sub-adult male $\left(\mathrm{F}_{1,6}=25.41, \mathrm{P}<0.05\right)$ sounders per study site during the dry season. Haro Aba Diko Controlled Hunting Area had more mean number of common warthog population sounders than GCHA during the dry season (Figure 6).

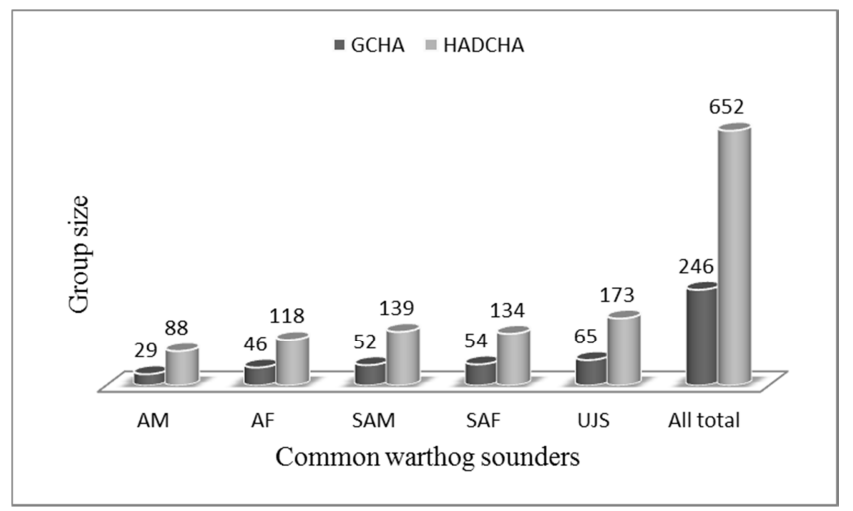

Figure 3. Common warthog group size in GCHA and HADCHA.

$\mathrm{AM}=$ adult male, $\mathrm{AF}=\mathrm{Adult}$ female, $\mathrm{SAM}=$ sub-adult male, $\mathrm{SAF}=$ sub-adult female, UJE=unidentified juvenile sex 


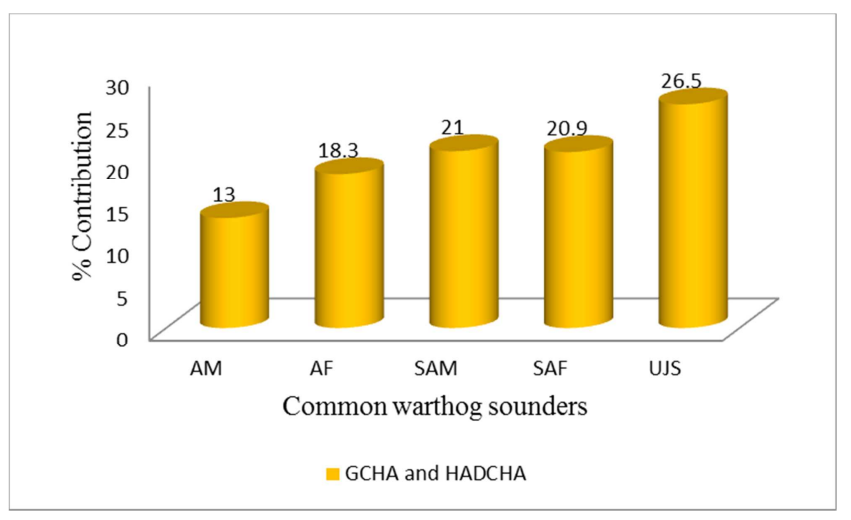

Figure 4. Common warthog sounder size contribution in both study areas.

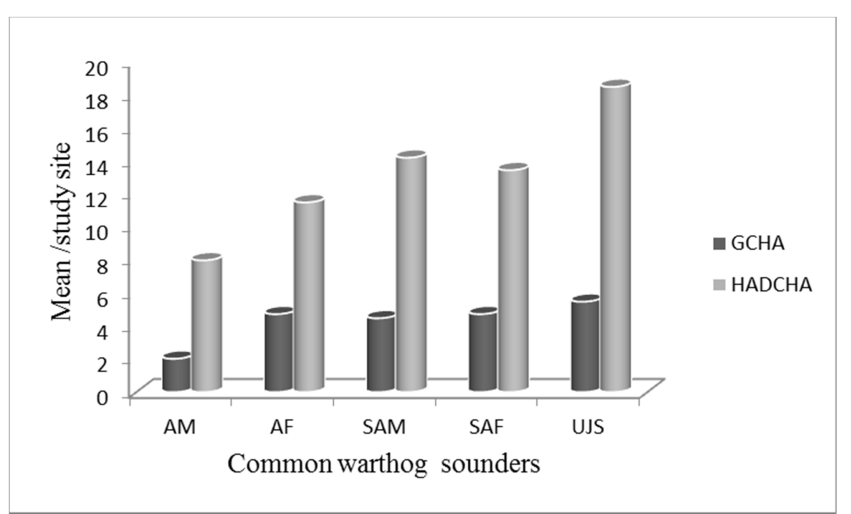

Figure 5. Common warthog sounder $M \pm S E$ per study site in GCHA and HADCHA during the wet season.

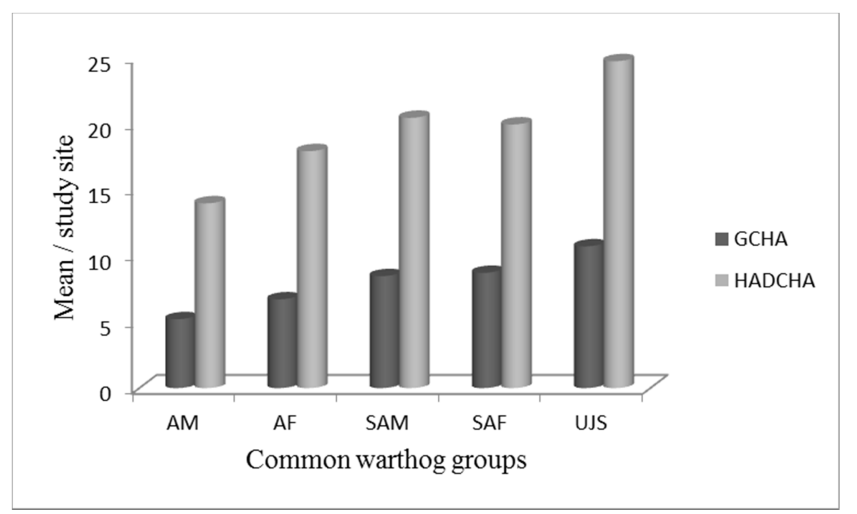

Figure 6. Common warthog sounder $M \pm S E$ per study site in GCHA and HADCHA during the dry season.

In GCHA, the mean duration of time adult females spent feeding was $7.62 \pm 0.48$ followed by resting $2.2 \pm 0.34$ during the dry season. During the wet season, the mean duration of time adult males allocated for feeding was $7.37 \pm 0.49$ followed by resting $(1.8 \pm 0.28)$. They did not show significant difference in feeding $\left(\mathrm{F}_{1,22}=0.13, \mathrm{P}>0.05\right)$ and resting $\left(\mathrm{F}_{1,22}=0.13, \mathrm{P}>0.05\right)$. However, the mean time adult males engaged in walking $(1.98 \pm 0.13)$ and vigilance $(1.75 \pm 0.16)$ was higher than adult females. Hence, adult males and adult females showed significant variation in walking $\left(\mathrm{F}_{1,22}=15.9\right.$, $\mathrm{P}<0.05)$ and in vigilance $\left(\mathrm{F}_{1,22}=19.64, \mathrm{P}<0.05\right)$ during the wet season in GCHA (Figure 7).

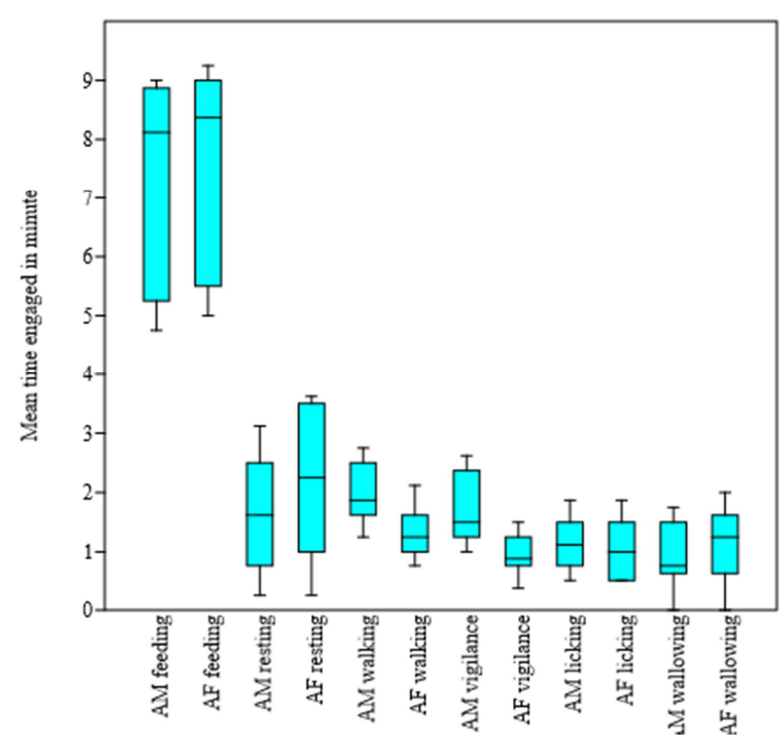

Sex and behavioral activities

Figure 7. Behavioral activity patterns of Adult male (AM) and Adult female (AF) common warthogs in GCHA during the wet season.

During the dry season, the mean duration time adult females engaged in feeding was $7.7 \pm 0.49$ followed by resting (2.4 \pm 0.33$)$. Similarly, the mean duration of time adult males spent feeding was $7.33 \pm 0.48$ followed by resting $(1.86 \pm 0.27)$ in GCHA. These were insignificantly different in feeding $\left(\mathrm{F}_{1,22}=0.17, \mathrm{P}>0.05\right)$ and resting $\left(\mathrm{F}_{1,22}=1.59, \mathrm{P}>0.05\right.$. However, the mean time adult males engaged in vigilance $(2.38 \pm 0.87)$ was higher than adult females $(1.99 \pm 0.86)$ in the same behavioral activity. Hence, they showed significant variation $\left(\mathrm{F}_{1,22}=9.8, \mathrm{P}<0.05\right)$ between adult males and adult females during the dry season in GCHA (Figure 8).

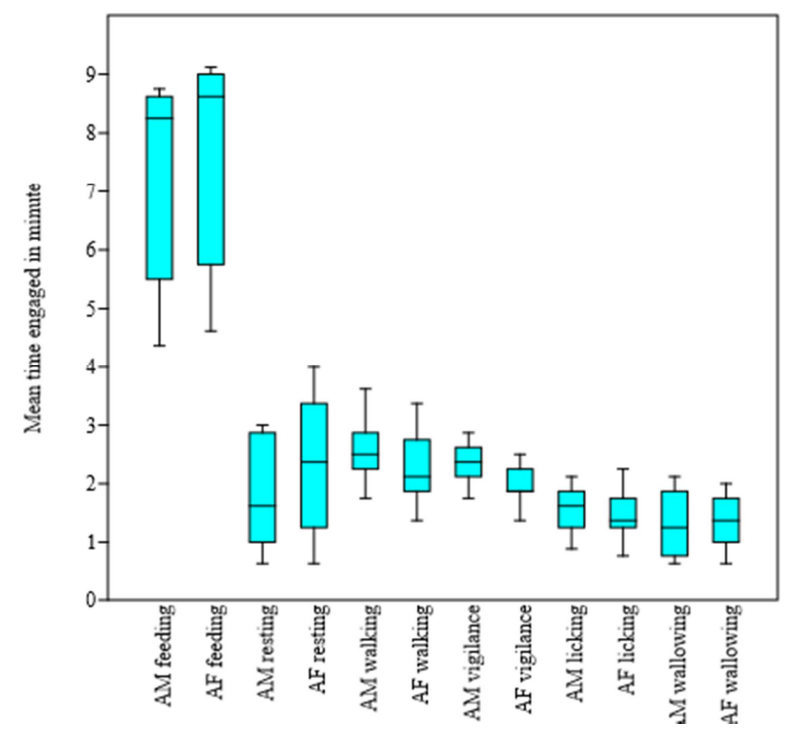

Sex and behavioral activities

Figure 8. Behavioral activity patterns of Adult male (AM) and Adult female (AF) common warthogs in GCHA during the dry season.

The mean time used by adult females feeding was $8.33 \pm 0.39$ which was $7.68 \pm 0.43$ by adult males during the 
wet season in HADCHA. However, there was no significant difference in feeding $\left(\mathrm{F}_{1,22}=1.2, \mathrm{P}>0.05\right)$ However, the mean time adult males spent for walking $(2.04 \pm 0.1)$ and vigilance $(1.52 \pm 0.16)$ was higher than that of adult females for walking $(1.42 \pm 0.11)$ and vigilance $(0.98 \pm 0.1)$. They revealed significant variation in walking $\left(\mathrm{F}_{1,22}=16.2, \mathrm{P}<0.05\right)$ and in vigilance $\left(\mathrm{F}_{1,22}=23.5, \mathrm{P}<0.05\right)$ during the wet season in HADCHA (Figure 9).

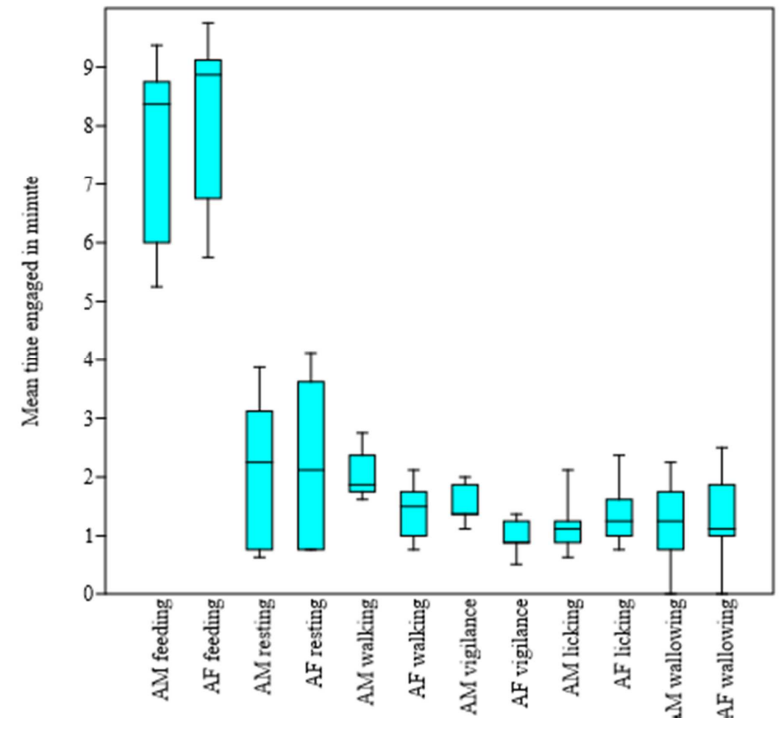

Sex and behavioral activities

Figure 9. Behavioral activity patterns of Adult male (AM) and Adult female (AF) common warthogs in HADCHA during the wet season.

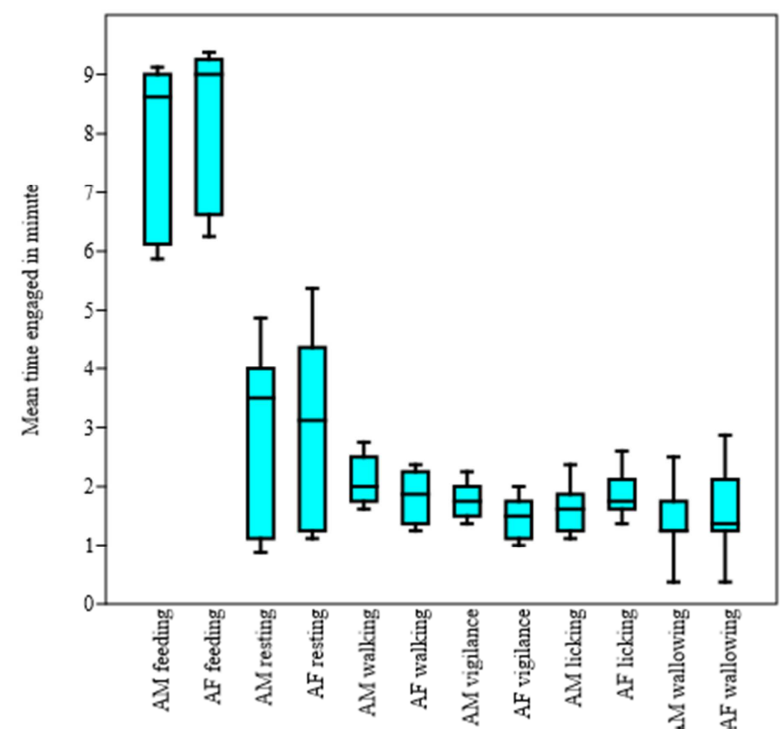

Sex and behavioral activities

Figure 10. Behavioral activity patterns of Adult male (AM) and Adult female (AF) common warthogs in HADCHA during the dry season.

During the dry season, the mean duration of time adult females engaged in feeding was $8.26 \pm 0.37$ followed by resting (3.15 \pm 0.33$)$. Similarly, the mean duration time adult males allocated for feeding was $7.96 \pm 0.38$ followed by resting $(2.93 \pm 0.4)$ in HADCHA. These showed insignificant differences in feeding $\left(\mathrm{F}_{1,22}=0.31, \mathrm{P}>0.05\right)$ and resting $\left(\mathrm{F}_{1,22}=0.13, \mathrm{P}>0.05\right)$. However, the mean duration of time adult males spent for vigilance $(1.79 \pm 0.07)$ was higher than that of adult females (1.48 \pm 0.08$)$. Hence, they showed significant variation $\left(\mathrm{F}_{1,22}=6.67, \mathrm{P}<0.05\right)$ during the dry season in HADCHA (Figure 10).

The mean duration of time adult females engaged in walking $(2.34 \pm 0.17)$ and in vigilance $(1.84 \pm 0.08)$ was more in GCHA than in HADCHA walking $(1.84 \pm 0.08)$ and vigilance (1.48 \pm 0.08$)$. Salt licking was higher in HADCHA $(1.88 \pm 0.2)$ than in GCHA $(1.44 \pm 0.1)$ during the dry season. There were no significant variations $(\mathrm{P}>0.05)$ in adult females engaged in feeding, resting and wallowing between GCHA and HADCHA (Table 2). In contrast, there were significant variations in walking $\left(\mathrm{F}_{1,22}=6, \mathrm{P}<0.05\right)$, vigilance $\left(\mathrm{F}_{1,22}=16.99, \mathrm{P}<0.05\right)$ and salt licking $\left(\mathrm{F}_{1,22}=7.24, \mathrm{P}<0.05\right)$ between the two study areas.

Table 2. Behavioral activities of Adult female (AF) warthogs in GCHA and HADCHA during the wet and dry seasons.

\begin{tabular}{lllll}
\hline Behavioral & GCHA & \multicolumn{3}{l}{ HADCHA } \\
\hline activities & Wet & Dry & Wet & Dry \\
\hline Feeding & $7.62 \pm 0.48$ & $7.7 \pm 0.49$ & $8.33 \pm 0.37$ & $8.27 \pm 0.32$ \\
Resting & $2.21 \pm 0.34$ & $2.4 \pm 0.33$ & $2.23 \pm 0.38$ & $3.15 \pm 0.33$ \\
Walking & $1.3 \pm 0.11$ & $2.34 \pm 0.17$ & $1.42 \pm 0.12$ & $1.84 \pm 0.08$ \\
Vigilance & $0.94 \pm 0.16$ & $1.99 \pm 0.86$ & $0.98 \pm 0.1$ & $1.48 \pm 0.08$ \\
Salt licking & $1.09 \pm 0.12$ & $1.44 \pm 0.1$ & $1.33 \pm 0.12$ & $1.88 \pm 0.2$ \\
Wallowing & $1.12 \pm 0.17$ & $1.38 \pm 0.11$ & $1.23 \pm 0.2$ & $1.6 \pm 0.19$ \\
\hline
\end{tabular}

The mean duration of time adult male allocated for feeding, resting, walking, vigilance, salt licking and wallowing in GCHA and HADCHA were comparable (Table 3). Hence, there were no significant variations $(\mathrm{P}>0.05)$ when adult male engaged in all behavioral activities between GCHA and HADCHA during the wet season.

During the dry season, adult males attained more mean duration time walking (2.6 \pm 0.16$)$ and vigilance $(2.38 \pm 0.87)$ in GCHA than walking $(2.09 \pm 0.1)$ and vigilance $(1.79 \pm 0.07)$ in HADCHA (Table 3). Hence, there were significant differences in walking $\left(\mathrm{F}_{1,22}=6.65, \mathrm{P}<0.05\right)$ and vigilance $\left(\mathrm{F}_{1,22}=26.21, \mathrm{P}<0.05\right)$ between GCHA and HADCHA. However, other behavioral activities showed insignificant variation between the study areas

Table 3. Behavioral activities of Adult male (AM) warthogs in GCHA and HADCHA during the wet and dry seasons.

\begin{tabular}{lllll}
\hline Behavioral & GCHA & \multicolumn{3}{l}{ HADCHA } \\
\hline activities & Wet & Dry & Wet & Dry \\
\hline Feeding & $7.37 \pm 0.49$ & $7.33 \pm 0.48$ & $7.68 \pm 0.43$ & $7.96 \pm 0.38$ \\
Resting & $1.8 \pm 0.28$ & $1.86 \pm 0.27$ & $2.11 \pm 0.32$ & $2.93 \pm 0.4$ \\
Walking & $1.98 \pm 0.13$ & $2.6 \pm 0.16$ & $2.04 \pm 0.1$ & $2.09 \pm 0.1$ \\
Vigilance & $1.75 \pm 0.16$ & $2.38 \pm 0.87$ & $1.52 \pm 0.08$ & $1.79 \pm 0.07$ \\
Salt licking & $1.0 .9 \pm 0.14$ & $1.44 \pm 0.11$ & $1.15 \pm 0.1$ & $1.61 \pm 0.1$ \\
Wallowing & $0.92 \pm 0.15$ & $1.35 \pm 0.15$ & $1.16 \pm 0.19$ & $1.42 \pm 0.16$ \\
\hline
\end{tabular}

Adult common warthogs spent the highest proportion of their daytime in feeding, followed by resting and walking. Less frequently observes behavioral activities were in salt licking and wallowing in GCHA and HADCHA during wet and dry seasons. Thus, there were significant differences 
observes $\left(\chi^{2}=18.91, \mathrm{df}=5, \mathrm{P}=0.05\right)$ in the proportion of time among diurnal activities in both the study areas (Table 4).

Table 4. Proportion of behavioral activities engaged by Adult female (AF) and Adult male (AM) common warthogs in GCHA and HADCHA during the wet and dry seasons.

\begin{tabular}{llllll}
\hline \multirow{2}{*}{ Activity } & GCHA & \multicolumn{3}{c}{ HADCHA } & Total \\
\cline { 2 - 6 } & \%AF & \%AM & \%AF & \%AM & \\
\hline Feeding & 11.73 & 11.23 & 12.52 & 11.73 & 47.21 \\
Resting & 3.49 & 2.8 & 4.31 & 3.69 & 14.29 \\
Walking & 2.77 & 3.52 & 2.48 & 3.17 & 11.94 \\
Vigilance & 2.24 & 3.18 & 1.91 & 2.55 & 9.88 \\
Salt licking & 1.94 & 2.11 & 2.48 & 2.12 & 8.65 \\
Wallowing & 1.91 & 1.8 & 2.19 & 1.99 & 7.89 \\
Total & & & & & 99.86 \\
\hline
\end{tabular}

\section{Discussion}

Group size is vital for precise estimation of wildlife population abundance [21]. It is influenced by availability of food, predation, and deforestation pressures. Predation, timing of the reproductive cycle and number of young born also put their impact on population group size [25]. The cost and benefits of grouping of individuals are mainly reliant on the amount of the groups with average individual fitness maximized at an optimal group size. The distribution of group size depends on the age and sex of the animals in a particular habitat [42]. In the present study, HADCHA comprised larger sounder size of common warthog population than GCHA. This might be due to lower resource competition, anthropogenic pressure, and predation risk in HADCHA than in GCHA. Other studies found lower common warthog group sizes than the present study in Diregudo Forest of Gololcha of southeast Ethiopia [1], iMfolozi Game Reserve (iGR) in the KwaZulu/Natal Province of South Africa. The finding in iMfolozi Game Reserve (iGR) in the KwaZulu/Natal Province of South Africa was higher than the one in the present study [42].

During the present study, unidentified juvenile sex followed by sub-adult male and females formed the highest common warthog population in the study areas during both seasons. The finding of the present study was consistent with the higher value of sub-adult female, unidentified juvenile sex and sub-adult males common warthog population groups but lower than adult females and males groups observed in Diregudo Forest of Gololcha of southeast Ethiopia [1]. Likewise, the finding of the present study was comparable with the one recorded in iMfolozi Game Reserve in the KwaZulu/Natal Province of South Africa [42]. In the present study, the numbers of adult males and sub-adult males of both study areas, unidentified juvenile sex in GCHA and sub-adult females of common warthog population groups in HADCHA were not influenced by season. In contrast, the number of adult females in both study areas and sub-adult females in GCHA and unidentified juvenile sex common warthog populations in HADCHA were influenced by season and significantly larger during the dry season than the wet season. Adult female common warthog group was related to changes in environmental variables and costs of reproduction during the wet season [42]. The finding of the present study was comparable with iMfolozi Game Reserve in the KwaZulu/Natal Province of South Africa that the number of adult males and unidentified juvenile sex were not influenced by season whereas the number of adult females was affected by seasonal variation [42].

Foraging increases heat load of the animal through muscular activity and exposure to direct and indirect solar radiation [23]. The mean time of adult females and adult females involved in feeding was not influenced by season. This might be due to both sexes exhibiting similar patterns of feeding behavior during both seasons. During the present study, there was no significant variation between GCHA and HADCHA in mean duration of time that both sexes spent feeding during both seasons. This might be due to the similarity in the pattern of feeding across the study areas and both sexes increased mean duration of time allocated for feeding to meet their daily energy requirements.

Common warthogs seek shade during the mid-day time block. They usually lack significant dermal fat, which facilitates heat dissipation [39]. The mean time of adult females and adult males engaged in resting was not impacted by season. This might be due to both sexes becoming equally sensitive to extreme high temperature and showing comparable patterns of resting behavior during both seasons. Moreover, there was no significant variation between GCHA and HADCHA in the mean duration of time adult females and adult males spent for resting during both seasons. This might be due to the uniformity of the daily ambient temperature of DVF in GCHA and HADCHA.

Ungulates are engaged in walking more when food availability is scarce or when food sources are patchily dispersed [19]. On the other hand, warthogs often walk away to avoid humans and predators [15]. The mean time adult females and adult males of common warthogs walked was not subjected by season in HADCHA. This could be due to the shortage of food during the hotter period in GCHA than in HADCHA. Hence, both sexes of common warthogs walked more in search of food during the dry season in GCHA than in HADCHA. There was no significant variation between GCHA and HADCHA in the mean duration of time that adult females and adult males spend for walking during the wet season. But, both sexes of common warthogs took more time to walk in GCHA than in HADCHA during the dry season. This might be due to the extended time taken for walking to look for food when biomass and quality of the ingested food decline during the dry season [23].

Vigilance requires limited resources such as time and visual attention [5]. Hence, vigilance conflicts with other behavioral activities, like feeding, resting, salt licking, and wallowing [37]. The mean duration of time that adult males took part in vigilance was subjected by season, and it was high during the dry season. This might be due high rate of vigilance in predation risk area. Females need high energy requirements for their offspring and prioritize foraging and 
they benefit from the presence of vigilant males [31, 37].

The need of salt in mammals is exhibited primarily in spring and summer and is attributed to seasonal needs of minerals in response to metabolic acquisition [22, 27]. During the current study, the mean time adult females of both study areas and adult males of GCHA engaged in salt licking was influenced by season. This might be due to the reproductive activity of adult females frequenting salt lick sites higher than their male counterparts in the study areas $[2,26]$. In the present study, there was no significant variation between GCHA and HADCHA in mean the duration of time both sexes spent for salt licking. This might be due to comparable warthog attraction of licking sites in the study areas.

Common warthogs lack functional sweat glands. Hence, they wallow in the mud to lower their body temperature. Wallowing also serves to combat ectoparasites by rubbing against trees [4]. The mean time adult females of both study areas and adult males of HADCHA engaged in wallowing varied based on season. Wallows are used frequently during the summer months when animals behaviorally try to reduce their heat load and thermoregulation [4]. In the present study, there was no significant variation between GCHA and HADCHA in the mean duration of time both sexes allocated for wallowing during both seasons. This might be due to insignificant variation of weather conditions in the present study areas.

\section{Conclusion}

Common warthogs socially exist in different sounder size. The highest common warthog population sounder was formed by UJS. Activity patterns of common warthogs were associated with ambient temperature and intensity of solar radiation in both study areas. However, there were significant difference among diurnal activities in the mean duration of time engaged by common warthog. These were based on their physiological interest and physical barrier avoidance. Similarly, there were variation between AF and AM in the mean length of time allocated for various diurnal activities. Season also affects the mean length of time engaged in different activities. Like many large herbivorous animals, common warthog population also spent majority of their diurnal time for feeding. Some activities showed inverse correlation with other behavioral activities. Thus, each behavioral activity of the common warthog peaked during its particular time block of the day.

\section{Acknowledgements}

We are grateful to Addis Ababa University, Department of Zoological Sciences for financial support from thematic project. We are also indebted to Oromia Forest and Wildlife Enterprise for the permit provided to conduct this research in Dabena Valley Forest. We also thank our respondents and field assistants for their willingness and support during the period of data collection.

\section{References}

[1] Abdu, A. and Datiko, D. 2017. Population size, habitat association of common warthog (Phacochoerus africanus) and their impact on agricultural crops around Diregudo forest in Gololcha Woreda, southeast, Ethiopia. I. J. Sci. Res. Publ. 7: 192-218.

[2] Ajayi, S. R. and Ogunjobi, J. A. 2015. Composition of large mammal daytime visitation to salt lick sites inside Kainji Lake National Park, Nigeria. Ife J. Sci. 17: 335-340.

[3] Ali, Y. S. A. 2014. The impact of soil erosion in the upper Blue Nile on downstream reservoir sedimentation. $\mathrm{Ph} \mathrm{D}$ thesis submitted to Delft University of Technology and the academic board of the UNESCO-the Institute for water education.

[4] Allwin, B., Swaminathan, R., Mohanraj, A., Suhas, G. N., Vedaminckam. S., Sathish Gopal, S. and Kumar, M. 2016. The wild pig (Sus scrofa) behavior: a retrospective study. J. Veterinar. Sci. Techno. 7: 1-10.

[5] Altmann, J. 1974. Observational study of behavior: sampling methods. Behav. 49: 227-267.

[6] Arenz, C. L. and Leger, W. D. 1999. Thirteen-lined ground squirrel (Sciuridae: Spermophilus tridecemlineatus) antipredator vigilance decreases as vigilance cost increases. Anim. behav. 57: 97-103.

[7] Awulachew, S. B., Yilma, A. D., Loiskandl, M. L., Ayana, M. and Alamirew, T. 2007. Water resources and irrigation development in Ethiopia. I. Wat. Manag. Inst. 123: 1-78.

[8] Betrie, G. D., Mohamed, Y. A., van Griensven, A. and Srinivasan, R. 2011. Sediment management modeling in the Blue Nile Basin using SWAT model. Hydrol. Eart. Syst. Sci. 15: $807-818$.

[9] Buckland, S. T., Plumptre, A. J., Thomas, L. and Rexstad, E. A. 2010. Line transects sampling of primates: can animal to observer distance methods work? Int. J. Primatol. 31: 485-499.

[10] Clauss, M., Streich, W. J., Schwarm, A., Ortmann, S. and Hummel, J. 2007. The relationship of food intake and ingesta passage predicts feeding ecology in two different mega herbivore groups. Oikos, 116: 209-216.

[11] Denes, F. V., Silveira, L. F. and Beissinger, S. R. 2015. Estimating abundance of unmarked animal populations: accounting for imperfect detection and other sources of zero inflation Meth. Ecol. Evol. 6: 543-556.

[12] Durand, E., Bluma, M. G. B., and Francoisa O. 2007. Prediction of group patterns in social mammals based on a coalescent model. J. Theoret. Biol. 249: 262-270.

[13] Fowler, M. E. 1996. Husbandry and diseases of captive wild swine and peccaries. Rev. Sci. Tech. Off. I. Epiz. 15: 141-154.

[14] Griffiths, N. 1978. Counting animals. A series of handbooks on techniques in African wildlife ecology, Nairobi, Kenya.

[15] Hjertlöv, L. 2015. Why do the common warthog Phacochoerus africanus stay at KichwaTembo. Skar. 620: 1-22.

[16] Jian-bin, S., Dunbar, R., Di-qiang, L. and Wen-fea, X. 2006. Influence of climate and day length on the activity budgets of feral goats (Capra hircus) on the Isle of Rum, Scotland. Zool. Res. 6: 561-568. 
[17] Kasiringua, E., Kopij, G., and Proche, S. 2017. Daily activity patterns of ungulates at water holes during the dry season in the Waterberg National Park, Namibia. Russ. J. Theriol. 16: $129-138$.

[18] Keuling, O. 2009. Managing wild boar - Considerations for wild boar management based on game biology data. $\mathrm{PhD}$ dissertation submitted to Dresden University of Technology.

[19] Mahenya, O. J. 2016. Browsing by giraffe in heterogeneous savanna. PhD thesis submitted to Inland Norway University, Faculty of Applied Ecology and Agricultural Sciences.

[20] Merid, F. 2002. National Nile Basin water quality monitoring baseline report for Ethiopia. In Nile Basin initiative transboundary environmental action project. Pp. 1-82.

[21] Msoffe, F. U., Ogutu, J. O., Kaaya, J., Bedelian, C., Said, M. Y., Kifugo, S. C., Reid, R. S., Neselle, M., van Gardingen, P. and Thirgood, S. 2009. Participatory wildlife surveys in communal lands: a case study from Simanjiro, Tanzania. Afr. J. Ecol. 48: 727-735.

[22] Nichols, R. V. 2012. Coexistence in ungulate communities: niches, resource partitioning, competition and facilitation. Introd. Resear. Essa. 17: 1-19.

[23] Owen-Smith, N. (1998). How high ambient temperature affects the daily activity and foraging time of a subtropical ungulate, the greater kudu (Tragelaphus strepsiceros). J. Zool. 246: $183-192$.

[24] Owen-Smith, N. and Traill, L. W. 2017. Space use patterns of a large mammalian herbivore distinguished by activity state: fear versus food? J. Zool. 69: 1-10. doi: 10.1111/jzo.12490.

[25] Patry, M., Leus, K. and Macdonald, A. A. 1995. Group Structure and Behavior of Babirusa (Babyrousa babyrussa) in Northern Sulawesi. Aust. J. Zool. 43: 643-655.

[26] Ping, X., Li, C., Jianga, Z., Liuc, W. and Zhuc, H. 2011. Sexual difference in seasonal patterns of salt lick use by south China Sika deer Cervusnippon. Mamm. Biol. 76: 196-200.

[27] Risenhoover, K. L. and Peterson, R. O. 1986. Mineral licks as a sodium source for Isle Royale moose. Oecologia 71: 121126.

[28] Rodrigues, F. H. G. and Monteiro-Filho, E. L. A. 2000. Home range and activity patterns of pampas deer in Emas National Park, Brazil. J. Mamm. 81: 1136-1142.

[29] Ryan, S. J. and Jordaan, W. 2005. Activity patterns of African buffalo Syncerus caffer in the Lower Sabie Region, Kruger National Park, South Africa. Koed, 48: 117-124.

[30] Shannon, G., Page, B. R., Mackey, R. L., Duffy, K. J. and Slotow, R. 2008. Activity budgets and sexual segregation in African elephants (Loxodonta africana). J. Mamm. 89: 467476.
[31] Simpson, H. I., Rands, S. A. and Nicol, C. J. 2012. Social structure, vigilance and behavior of plains zebra (Equus burchellii): a 5-year case study of individuals living on a managed wildlife reserve. Acta. Theriol. 57: 111-120.

[32] Strindberg, S. 2012. Distance sampling along line transects: statistical concepts and analysis options. In: Monitoring Elephant Populations and Assessing Threats a Manual for Researchers, Managers and Conservationists, Hedges, S. (Ed.) Universities Press, Pltd, India, pp. 26-60.

[33] Svemer, F. (2010). Mating behavior and hierarchy among male warthogs (Phacochoerus africanus) in Kenya. Skar. 102: $1-20$.

[34] Swanepoel, M. 2016. Distribution, utilization and management of the extra-limital common warthog (Phacochoerus africanus) in South Africa. $\mathrm{PhD}$ thesis submitted to Stellenbosch University, Faculty of Arisciences,

[35] Swanepoel, M, Schulze, E. and Cumming, D. H. M. 2016. A conservation assessment of Phacochoerus africanus. The Red List of Mammals of South Africa, Lesotho and Swaziland. Pp. $1-7$.

[36] Thomas, L., Buckland, S. T., Rexstad, E. A., Laake, J. L., Strindberg, S., Hedley, S. L., Bishop, J. R. B., Marques, T. A. and Burnhad, K. P. 2009. Distance software: design and analysis of distance sampling surveys for estimating population size. J. Appl. Ecol. 64: 1-9.

[37] Treves, A. 2000. Theory and method in studies of vigilance and aggregation. Anim. Behav. 60: 711-722.

[38] Treydte, A. C., Bernasconi, S. M., Kreuzer, M. and Edwards, P J. 2006. Diet of the common warthog (Phacochoerus africanus) on former cattle grounds in a Tanzanian Savanna. J. Mamm. 87: 889-898.

[39] Vercammen, P. and Mason, D. R. 1993. The warthogs (Phacochoerus africanus and P. aethiopicus). In: Status Survey and Conservation Plan of Pigs, Peccaries, and Hippos, Oliver, W. L. R. (Ed.). IUCN Gland, Switzerland, pp. 75-83.

[40] Walter, W. D., Fischer, J. W., Frink, T. J., Hygnstrom, S. E., Jenks, J. A. and Vercauteren, K. C. 2013. Topographic home range of large mammals: Is planimetric home range still a viable method? Prair. Natur. 45: 21-27.

[41] Wanyama, F., Muhabwe, R., Plumptre, A. J. and Chapman C. A. 2009. Censusing large mammals in Kibale National Park: evaluation of the intensity of sampling required to determine change. Afr. J. Ecol. 48: 953-961.

[42] White, A. M. 2010. A pigheaded compromise: do competition and predation explain variation in warthog group size? Behav. Ecol. 1093: 1-8. 